\title{
Faktor - Faktor Yang Berhubungan Dengan Perilaku Pemeliharaan Kebersihan Gigi Dan Mulut di Kelurahan Wonoharjo Kabupaten Tanggamus
}

\author{
Ariyanto \\ Jurusan Keperawatan Gigi Poltekkes Tanjungkarang
}

\begin{abstract}
Abstrak
Gigi merupakan salah satu bagian tubuh yang berfungsi untuk mengunyah, berbicara dan mempertahankan bentuk muka.Mengingat kegunaannya yang sangat penting maka perlu untuk menjaga kesehatan gigi dan mulut agar gigi dapat bertahan lama dalam rongga mulut. Menjaga kebersihan gigi dan mulut sangatlah penting, karena menjaga agar mulut tetap bersih, mencegah infeksi pada rongga mulut, serta untuk meningkatkan daya tahan tubuh. Tingginya penyakit gigi dan mulut sangat dipengaruhi oleh beberapa faktor yang salah satunya adalah faktor perilaku masyarakat yang belum menyadari pentingnya memelihara kesehatan gigi dan mulut. Jenis peneliitian ini adalah kuantitatif dengan desain penelitian analitik. Teknik pengumpulan data dengan pendekatan cross sectional yaitu mengadakan pengamatan hanya sekali terhadap beberapa variabel dan diukur pada saat bersamaan. Lokasi penelitian dilakukan di Kelurahan Wonoharjo Kabupaten Tanggamus dengan jumlah sampel 284 orang. Analisa data yang dilakukan dengan cara univariat, bivariat dengan Chi Square dan multivariat dengan regresi logistic. Hasil analisis bivariat variabel yang berhubungan dengan perilaku pemeliharaan kebersihan gigi dan mulut adalah pengetahuan pemeliharaan kebersihan gigi dan mulut $(\mathrm{p}=0,044)$, sikap tentang pemeliharaan kebersihan gigi dan mulut $(p=0,018)$, tindakan pemeliharaan kebersihan gigi dan mulut $(p=0,013)$. Hasil uji regresi logistic diperoleh hasil yang paling dominan berpengaruh terhadap pemeliharaan kebersihan gigi dan mulut adalah variabel tindakan responden $(\mathrm{OR}=1,749)$
\end{abstract}

Kata kunci $\quad$ : Perilaku, Pemeliharaan kebersihan gigi dan mulut

\section{Factors Related to Behavior of Maintenance of Tooth And Mouth Hygiene in Wonoharjo Sub-district, Tanggamus District}

\begin{abstract}
Teeth is one part of the body that serves to chew, talk and maintain face shape. Given its usefulness is very important it is necessary to maintain healthy teeth and mouth for teeth can last long in the oral cavity. Maintaining oral hygiene is very important, because it keeps the mouth clean, prevents infection in the oral cavity, and to increase endurance. High dental and oral diseases are strongly influenced by several factors, one of which is the behavioral factor of people who have not realized the importance of maintaining oral health.

This type of research is quantitative with analytic research design. . The data collection technique with cross sectional approach is to hold only one observation on several variables and measured at the same time. The location of the research was conducted in Wonoharjo District of Tanggamus Regency with a total sample of 284 people. Data analysis conducted by univariate, bivariate with Chi Square and multivariate with logistic regression. The result of bivariate analysis of the variables related to dental and oral hygiene maintenance behavior was knowledge of dental and oral hygiene maintenance $(p=0,044)$, attitude about dental and oral hygiene maintenance $(\mathrm{p}=0,018)$, dental and mouth hygiene $(\mathrm{p}=0,013)$. Logistic regression test results obtained the most dominant effect on the maintenance of oral hygiene is the respondent's action variable $(\mathrm{OR}=$ $1,749)$
\end{abstract}

Keywords: Behavior, Maintenance of dental and oral hygiene

Korespondensi: Arianto, Jurusan Keperawatan Gigi, Politeknik Kesehatan Tanjungkarang, Jalan SoekarnoHatta No. 1 Hajimena Bandar Lampung, mobile 082183416882,e-mail arianto.arianto@roketmail.com 


\section{Pendahuluan}

Kesehatan merupakan bagian terpenting dalam kehidupan manusia, baik sehat secara jasmani maupun rohani. Kesehatan yang perlu diperhatikan selain kesehatan tubuh secara umum, juga kesehatan gigi dan mulut. Kesehatan gigi dan mulut merupakan salah satu hal yang penting dalam menjaga keseimbangan fungsi tubuh. Gigi merupakan salah satu bagian tubuh yang berfungsi untuk mengunyah, berbicara dan mempertahankan bentuk muka. Mengingat kegunaannya yang sangat penting maka perlu untuk menjaga kesehatan gigi dan mulut agar gigi dapat bertahan lama dalam rongga mulut. Karies gigi dan penyakit periodontal umumnya disebabkan oleh kebersihan mulut yang buruk (Pintauli S, 2008).

Oral hygiene merupakan tindakan untuk membersihkan dan menyegarkan mulut, gigi dan gusi (Clark, 2005). Oral Hygiene (kebersihan gigi dan mulut) dalam kesehatan gigi dan mulut sangatlah penting, karena menjaga agar mulut tetap bersih, mencegah infeksi pada rongga mulut, serta untuk meningkatkan daya tahan tubuh. Beberapa masalah gigi dan mulut dapat terjadi karena kurangnya kesadaran masyarakat dalam menjaga kebersihan gigi dan mulut antara lain lubang gigi, gusi berdarah, bau mulut, serta terjadinya penumpukan plak dan karang gigi (Herjulianti E, 2001).

Penyakit gigi dan mulut merupakan penyakit masyarakat yang dapat menyerang semua golongan umur mulai dari anak anak sampai orang dewasa. Tingginya penyakit gigi dan mulut sangat dipengaruhi oleh beberapa faktor yang salah satunya adalah faktor perilaku masyarakat yang belum menyadari pentingnya memelihara kesehatan gigi dan mulut. Prilaku memiliki peran penting untuk mempengaruhi status kesehatan gigi dan mulut (Ariningrum, 2000).

Berdasarkan teori Blum, status kesehatan gigi dan mulut seseorang atau masyarakat dipengaruhi oleh empat faktor yaitu keturunan, lingkungan, perilaku dan pelayanan kesehatan. Perilaku mempunyai peran penting untuk mempengaruhi standar kesehatan gigi dan mulut. Perilaku dalam memelihara kesehatan dipengaruhi oleh faktor pengetahuan, sikap dan tindakan atau praktik. (Notoatmdjo S, 2007). Meningkatkan pengetahuan dan sikap akan menigkatkan kesadaran masyarakat dalam menjaga kesehatan.

Penelitian yang dilakukan oleh Smyth dkk (2007), masyarakat yang mempunyai pengetahuan yang tinggi mengenai kesehatan gigi dan mulut memiliki sikap dan praktik atau tindakan yang baik dalam menjaga kebersihan gigi dan mulut (Lian CW, 2010). Baik buruknya kebersihan gigi dan mulut ditentukan oleh perilaku seseorang. Pemeliharaan kebersihan gigi dan mulut yang tidak benar menyebabkan mudahnya penumpukan plak, kalkulus yang pada akhirnya akan merusak kesehatan gigi.

Data Riskesdas (2013) sebesar 25,9\% penduduk Indonesia mempunyai masalah gigi dan mulut dalam 12 bulan terakhir (potential demand). Diantara mereka, terdapat $31,1 \%$ yang menerima perawatan dan pengobatan dari tenaga medis gigi (perawat gigi, dokter gigi atau dokter gigi spesialis), sementara 68,9\% lainnya tidak dilakukan perawatan. Prevalensi penduduk provinsi Lampung yang mempunyai masalah kesehatan gigi dan mulut $15,3 \%$. hal tersebut menunjukan bahwa masih kurangnya pengetahuan masyarakat tentang kesehatan gigi dan mulut. Kebiasaan menggosok gigi setiap hari masyarakat Lampung 96,1\%, tetapi yang menyikat gigi dengan benar hanya $0,4 \%$. Angka tersebut masih dibawah rata rata nasional yaitu 2,3\%. Untuk kabupaten Tanggamus prevalensi penduduk yang yang mempunyai masalah kesehatan gigi dan mulut 20,2 \%. Kebiasaan menggosok gigi setiap hari $97,6 \%$, waktu menyikat gigi cenderung dilakukan pada saat mandi pagi $99,5 \%$ dan pada saat mandi sore $96,5 \%$. Tetapi waktu menyikat gigi yang benar yang dilakukan setelah sarapan pagi hanya 1,0 $\%$ dan sebelum tidur malam $4,2 \%$.

\section{Metode}

Jenis penelitian ini adalah kuantitatif dengan desain penelitian analitik. Teknik pengumpulan data dengan pendekatan cross sectional yaitu mengadakan pengamatan hanya sekali terhadap beberapa variable dan diukur pada saat bersamaan. Penelitian dilaksanakan di Kelurahan Wonoharjo Kabupaten Tanggamus. Waktu penelitian dilaksanakan pada bulan Juli 2018. Jumlah responden sebanyak 284 orang.

\section{Hasil}

Dari penelitian yang telah dilakukan didapatkan sebagai berikut:

\section{Analisis Univariat}


Tabel 1. Pengetahuan, sikap, tindakan dan perilaku responden

\begin{tabular}{|l|c|c|}
\hline Pengetahuan & Frekuensi & Persentase (\%) \\
\hline Baik & 161 & 56.7 \\
\hline Kurang & 123 & 43.3 \\
\hline Total & 284 & 100 \\
\hline Sikap & \multicolumn{2}{|l|}{} \\
\hline Baik & 151 & 53.2 \\
\hline Kurang & 133 & 46.8 \\
\hline Total & 284 & 100 \\
\hline Tindakan & \multicolumn{2}{|l|}{} \\
\hline Baik & 150 & 52.8 \\
\hline Kurang & 134 & 47.2 \\
\hline Total & 284 & 100 \\
\hline Perilaku & \multicolumn{2}{|l|}{} \\
\hline Baik & 129 & 45.4 \\
\hline Kurang & 155 & 54.6 \\
\hline Total & 284 & 100,0 \\
\hline
\end{tabular}

\section{Analisis Bivariat}

Tabel 2. Hubungan pengetahuan dengan perilaku pemeliharaan kebersihan gigi dan mulut

\begin{tabular}{|l|c|c|c|c|c|c|}
\hline \multirow{2}{*}{ Pengetahuan } & \multicolumn{2}{|l|}{$\begin{array}{l}\text { Perilaku pemeliharaan } \\
\text { kebersihan gigi dan } \\
\text { mulut }\end{array}$} & \multicolumn{2}{|c|}{ Total } \\
\cline { 2 - 7 } & Baik & \multicolumn{2}{|l|}{ Buruk } & \multicolumn{2}{|c|}{} \\
\cline { 2 - 7 } & f & \% & f & \% & f & \% \\
\hline \multirow{2}{*}{ Baik } & 82 & 50,9 & 79 & 49,1 & 161 & 100 \\
\hline Kurang & 47 & 38,2 & 76 & 61,8 & 123 & 100 \\
\hline
\end{tabular}

Tabel 3. Hubungan Sikap dengan perilaku pemeliharaan kebersihan gigi dan mulut

\begin{tabular}{|l|c|c|c|c|c|c|}
\hline \multirow{2}{*}{ Sikap } & \multicolumn{3}{|l|}{$\begin{array}{l}\text { Perilaku pemeliharaan } \\
\text { kebersihan gigi dan } \\
\text { mulut }\end{array}$} & \multicolumn{2}{|c|}{ Total } \\
\cline { 2 - 7 } & \multicolumn{2}{|c|}{ Baik } & \multicolumn{2}{|c|}{ Buruk } & \multicolumn{2}{|c|}{ f } \\
\cline { 2 - 7 } & $\mathbf{f}$ & $\mathbf{\%}$ & $\mathbf{f}$ & $\mathbf{6}$ & $\%$ \\
\hline \multirow{2}{*}{ Baik } & 79 & 52,3 & 72 & 47,7 & 151 & 100 \\
\hline \multirow{2}{*}{ Kurang } & 50 & 37,6 & 83 & 62,4 & 133 & 100 \\
\hline
\end{tabular}

Tabel 4. Hubungan tindakan dengan perilaku pemeliharaan kebersihan gigi dan mulut

\begin{tabular}{|l|c|c|c|c|c|c|}
\hline \multirow{2}{*}{ Tindakan } & \multicolumn{3}{|c|}{$\begin{array}{c}\text { Perilakupemeliharaan } \\
\text { kebersihan gigi dan mulut }\end{array}$} & \multicolumn{2}{|c|}{ Total } \\
\cline { 2 - 6 } & \multicolumn{2}{|c|}{ Baik } & \multicolumn{2}{c|}{ Buruk } & \multicolumn{2}{|c|}{} \\
\cline { 2 - 7 } & F & $\%$ & f & $\%$ & f & $\%$ \\
\hline Baik & 79 & 52,7 & 71 & 47,3 & 150 & 100 \\
\hline Kurang & 50 & 37,3 & 84 & 62,7 & 134 & 100 \\
\hline
\end{tabular}

\section{Analisis Multivariat}

Tabel 5. Hasil Uji Multivariat

\begin{tabular}{|l|r|r|r|r|r|r|r|r|}
\hline $\begin{array}{l}\text { Varia } \\
\text { bel }\end{array}$ & B & S.E. & Wald & df & Sig. & $\begin{array}{c}\text { Exp } \\
\text { (B) }\end{array}$ & \multicolumn{2}{|c|}{$\begin{array}{c}\text { 95.0\% C.I.for } \\
\text { EXP(B) }\end{array}$} \\
\hline $\begin{array}{l}\text { Tinda } \\
\text { kan }\end{array}$ & .559 & .246 & 5.175 & 1 & .023 & 1.749 & 1.080 & 2.830 \\
\hline $\begin{array}{l}\text { Consta } \\
\text { nt }\end{array}$ & -320 & .192 & 2.759 & 1 & .097 & .726 & & \\
\hline
\end{tabular}

\section{Pembahasan}

Perilaku Pemeliharaan Kebersihan Gigi dan Mulut di Kelurahan Wonoharjo Kabupaten Tanggamus

Hasil penelitian menunjukkan bahwa perilaku masyarakat dalam memelihara kebersihan gigi dan mulut di Kelurahan Wonoharjo Kabupaten Tanggamus dengan kategori kurang 54,6\% lebih banyak dibandingkan dengan kategori baik $45,4 \%$. Perilaku yang kurang baik dalam memelihara kebersihan gigi dan mulut diantaranya adalah gerakan menggosok gigi bagian permukaan gigi yang menghadap ke pipi tidak benar $71,1 \%$. Gerakan menggosok gigi bagian permukaan gigi yang menghadap ke bibir tidak benar $66,9 \%$.

Gerakan menggosok gigi untuk permukaan kunyah rahang bawah tidak benar $64,8 \%$. Gerakan menggosok gigi untuk permukaan kunyah rahang atas tidak benar $59,2 \%$. Gerakan menggosok gigi yang menghadap permukaan langit langit tidak benar $39,1 \%$. lama waktu menggosok gigi yang masih kurang 35,6\%dan waktu menggosok gigi yang salah $12,7 \%$.

Hal ini memperlihatkan bahwa masyarakat untuk berperilaku positif di bidang kesehatan gigi dan mulut belum optimal. Perilaku masyarakat tentang menggosok gigi akan mempengaruhi baik atau buruknya kebersihan gigi dan mulut. Masyarakat belum memahami atau tidak tahu cara menggosok gigi yang benar dan lamanya menggosok gigi. masyarakat hanya sebatas memahami menggosok gigi yang penting gigi sudah disikat.masyarakat kurang menyadari bahwa menggosok gigi harus memperhatikan gerakan menggosok gigi pada setiap permukaan gigi.

Perilaku masyarakat dalam menggosok gigi akan lebih mudah apabila masyarakat tersebut tahu apa manfaat menggosok gigi, tahu cara menggosok gigi yang benar dan tahu akibat atau dampak bila tidak menggosok gigi. Perilaku juga akan dipermudah apabila masyarakat yang bersangkutan mempunyai sikap yang positif terhadap perilaku menggosok gigi (Notoadmodjo S, 2010).

Tindakan Responden Terhadap Perilaku Pemeliharaan Kebersihan Gigi dan Mulut di Kelurahan Wonoharjo Kabupaten Tanggamus. 
Dari hasil penelitian didapatkan p.value $=$ 0,023 dan odds ratio $(\mathrm{OR})$ atau $(\operatorname{Exp} \mathrm{B})=1,749$ artinya tindakan yang baik mempunyai kemungkinan masyarakat untuk berperilakumemelihara kebersihan gigi dan mulut yang baik sebanyak 2 kali lebih besar dibandingkan dengan tindakan yang kurang. Perilaku pemeliharaan kebersihan gigi dan mulut yang buruk lebih banyak terdapat pada kelompok masyarakat yang kurang melakukan tindakan $62,7 \%$ dibandingkan denganmasyarakat yang melakukan tindakan47,3\%.Sedangkan persentase perilaku pemeliharaan kebersihan gigi dan mulutyang baik lebih banyak terdapat pada kelompok masyarakat yangmelakukan tindakan 52,7\% dibandingkan dengan kelompok masyarakat yang kurang melakukan tindakan 37,3\%. Tindakan masyarakat dalam memelihara kebersihan gigi dan mulut yang kurang dapat dilihat jawaban responden berpendapat bahwa tidak pernah pergi ke puskesmas atau ke dokter gigi untuk memeriksakan gigi. Sebesar 85,2\% responden juga berpendapat bahwa menggosok gigi dilakukan hanya pada waktu mandi saja. Sebesar $73,2 \%$ responden berpendapat bahwa menggosok giginya masih menggunakan sikat gigi yang bergantian dengan keluarganya.

Hasil uji statistik diperoleh p.value $=0,013$, karena p.value $\alpha$ maka Ha diterima, dan Ho ditolak, sehingga dapat diinterpretasikan bahwa ada hubungan yang signifikan antara tindakan responden dengan perilaku pemeliharaan kebersihan gigi dan mulut di Kelurahan Wonoharjo Kabupaten Tanggamus.

\section{Pengetahuan Responden dengan Perilaku Pemeliharaan Kebersihan Gigi dan Mulut di Kelurahan Wonoharjo Kabupaten Tanggamus}

Tingkat pengetahuan masyarakat tentang pemeliharaan kebersihan gigi dan mulut akan mempengaruhi baik atau buruknya kebersihan gigi dan mulut. Namun seseorang yang berpengetahuan tinggi saja belum cukup untuk mempengaruhi kebersihan gigi dan mulut menjadi baik apabila pengetahuan tersebut belum diterapkan dalam perilaku sehari-hari. Masyarakat belum memahami bagaimana cara menggosok gigi yang benar dan masyarakat juga belum tahu lamanya waktu dalam menggosok gigi. Masyarakat hanya sebatas memahami menggosok gigi yang penting gigi sudah disikat. masyarakat kurang menyadari bahwa menggosok gigi harus memperhatikan gerakan menggosok gigi pada setiap permukaan gigi.

Temuan penelitian menunjukkan bahwa responden yang berpengetahuan baik yaitu 161 orang $(56,7 \%)$ dan responden dengan pengetahuan kurang yaitu 123 orang $(43,3 \%)$. Perilaku pemeliharaan kebersihan gigi dan mulut yang buruk lebih banyak terdapat pada kelompok masyarakat yang berpengetahuan kurang61,8\%dibandingkan denganmasyarakat yang berpengetahuan baik $49,1 \%$.
Hasil uji korelasi dengan Chi square dengan $\mathrm{CI}=95 \%(\alpha=0,05)$ diperoleh p.value $=0,044$, karena p.value $<\alpha$ maka Ho ditolak, dan Ha diterima, sehingga dapat diinterpretasikan bahwa ada hubungan yang signifikan antara pengetahuan responden dengan perilaku pemeliharaan kebersihan gigi dan mulut di Kelurahan Wonoharjo Kabupaten Tanggamus.

\section{Sikap Responden denganPerilakuPemeliharaan Kebersihan Gigi dan Mulut di Kelurahan Wonoharjo Kabupaten Tanggamus}

Sikap Responden dengan Perilaku pemeliharaan kebersihan gigi dan mulut yang buruk lebih banyak terdapat pada kelompok masyarakat yang bersikap kurang baik $62,4 \%$ dibandingkan dengan masyarakat yang bersikap baik47,7\%. Sedangkan persentase perilaku pemeliharaan kebersihan gigi dan mulutyang baik lebih banyak terdapat pada kelompok masyarakat yangbersikap baik 52,3\% dibandingkan dengan kelompok masyarakat yang bersikapkurang baik $37,6 \%$.

Hasil uji korelasi dengan Chi square dengan $\mathrm{CI}=95 \%(\alpha=0,05)$ diperoleh $p$.value $=0,018$, karena p.value $<$ maka Ha diterima, dan Ho ditolak, sehingga dapat diinterpretasikan bahwa ada hubungan yang signifikan antara sikap responden dengan perilaku pemeliharaan kebersihan gigi dan mulut di Kelurahan Wonoharjo Kabupaten Tanggamus.

Sikap dan keyakinan masyarakat tentang perilaku memelihara kebersihan gigi dan mulut menjadi dasar bagi masyarakat untuk melakukan suatu aktivitas atau perilaku yang berkaitan dengan kesehatan gigi dan mulut.

Sikap merupakan reaksi atau respon seseorang yang masih tertutup terhadap stimulus atau objek. ( Notoadmodjo S, 2010). Adanya sikap yang baik bisa menjadikan perilaku yang positif, ini menunjukan bahwa sikap yang terjadi pada diri masyarakat banyak yang masuk dalam kategori sikap yang positif.Sedangkan belum optimalnya perubahan perilaku yang terjadi, ada kemungkinan dikarenakan sikap yang ada belum direalisasikan dalam bentuk tindakan/praktik yang positif.

\section{Daftar Pustaka}

1. Arikunto, Suharsimi, 2008, Prosedur Penelitian Suatu Pendekatan Praktik,Rineka Cipta, Jakarta

2. Ariningrum R. 2000. Beberapa Cara Menjaga Kebersihan Gigi dan Mulut. Cermin Dunia Kedokteran

3. Clark, M. and Kumar, P., , 2005. Clinical Medicine. 6th ed. London, UK: Elseveir Saunders. 
4. Endah, Kusumawardani 2011 Buruknya Perawatan Mulut Jakarta

5. Green LW, and Kreuter M.W. 2000. Health Promotion Planning An Education and Environmental Approach

6. Herijulianti, E,2001. Pendidikan Kesehatan Gigi. EGC. Jakarta

7. Lian CW, Baharudin LH. 2010. Oral Health Knowledge Attitude and Practice Among Scondary School Student in Kuching. Sarawak Archiver of Orofacial sciencer.

8. Notoatmodjo S. 2007. Promosi Kesehatan dan Ilmu Perilaku. Rineka Cipta. Jakarta

9. Notoatmodjo S.2010. Promosi Kesehatan. Teori dan Aplikasinya. Rineka Cipta. Jakarta

10. Pintauli S, dkk, 2008, Menuju gigi dan mulut sehat Pencegahan dan Pemeliharaan. EGC. Jakarta

11. Riskesdas 2013, Riset Kesehatan Dasar, Balai penelitian dan pengembangan kesehatan.Jakarta 